San Jose State University

SJSU ScholarWorks

Master's Theses

Master's Theses and Graduate Research

2002

\title{
Food habits of nesting Northern Goshawks in the Warner \\ Mountains, California
}

Rebecca Lynn Promessi

San Jose State University

Follow this and additional works at: https://scholarworks.sjsu.edu/etd_theses

\section{Recommended Citation}

Promessi, Rebecca Lynn, "Food habits of nesting Northern Goshawks in the Warner Mountains, California" (2002). Master's Theses. 2372.

DOI: https://doi.org/10.31979/etd.qez2-2fs2

https://scholarworks.sjsu.edu/etd_theses/2372

This Thesis is brought to you for free and open access by the Master's Theses and Graduate Research at SJSU ScholarWorks. It has been accepted for inclusion in Master's Theses by an authorized administrator of SJSU ScholarWorks. For more information, please contact scholarworks@sjsu.edu. 


\section{INFORMATION TO USERS}

This manuscript has been reproduced from the microfilm master. UMI films the text directly from the original or copy submitted. Thus, some thesis and dissertation copies are in typewriter face, while others may be from any type of computer printer.

The quality of this reproduction is dependent upon the quality of the copy submitted. Broken or indistinct print, colored or poor quality illustrations and photographs, print bleedthrough, substandard margins, and improper alignment can adversely affect reproduction.

In the unlikely event that the author did not send UMI a complete manuscript and there are missing pages, these will be noted. Also, if unauthorized copyright material had to be removed, a note will indicate the deletion.

Oversize materials (e.g., maps, drawings, charts) are reproduced by sectioning the original, beginning at the upper left-hand comer and continuing from left to right in equal sections with small overlaps.

ProQuest Information and Learning 300 North Zeeb Road, Ann Arbor, Mi 48106-1346 USA 800-521-0600

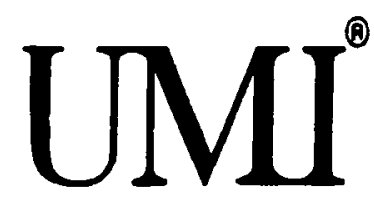





\title{
FOOD HABITS OF NESTING NORTHERN GOSHAWKS \\ IN THE WARNER MOUNTAINS, CALIFORNIA
}

\author{
A Thesis \\ Presented to \\ The Faculty of the Department of Biology \\ San Jose State University \\ In Partial Fulfillment \\ of the Requirements for the Degree \\ Master of Science
}

by

Rebecca Lynn Promessi

-

December 2002 
UMI Number: 1411625

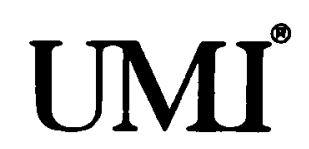

UMI Microform 1411625

Copyright 2003 by ProQuest Information and Learning Company.

All rights reserved. This microform edition is protected against unauthorized copying under Title 17, United States Code.

ProQuest Information and Learning Company 300 North Zeeb Road

P.O. Box 1346

Ann Arbor, MI 48106-1346 
(C) 2002

Rebecca Lynn Promessi

ALL RIGHTS RESEKVED 
APPROVED FOR THE DEPARTMENT OF BIOLOGY
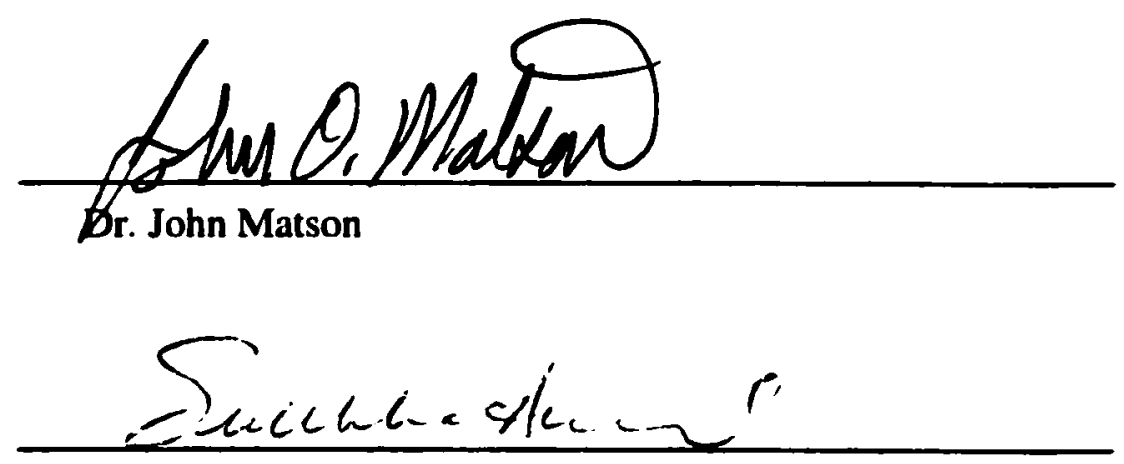

Dr. Sulekha Anand

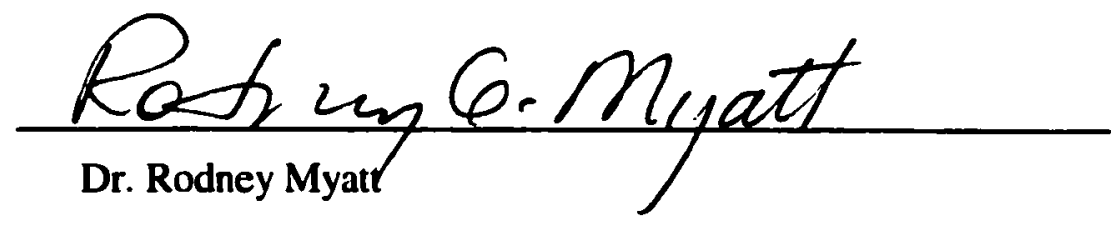

APPROVED FOR THE UNIVERSITY

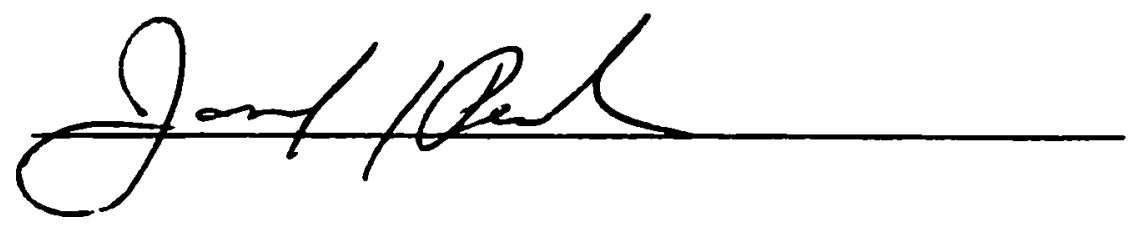




\section{ABSTRACT \\ FOOD HABITS OF NESTING NORTHERN GOSHAWKS IN THE WARNER MOUNTAINS, CALIFORNIA \\ by Rebecca Lynn Promessi}

The diet of Northern Goshawks (Accipiter gentilis) in the Warner Mountains of California was determined through an analysis of pellet contents and prey remains. A total of 33 samples from 23 nest sites was collected and analyzed. Prey items were quantified using two different methods: determining the minimum number of unique individuals, and determining the total number of occurrences of species. Northern Goshawks in the Warner Mountains preyed more heavily on mammalian than avian prey items. A minimum of 221 individuals was identified. Of these, 95 (42.99\%) were determined to be birds, while $126(57.01 \%)$ were determined to be mammals. Based on total number of occurrences, 162 (40.60\%) instances of birds and $237(59.40 \%)$ instances of mammals were recorded. In addition, the habitat composition of active nesting sites was evaluated. Nests were located in conifer stands having a high degree of canopy cover and containing large diameter trees. 


\section{ACKNOWLEDGEMENTS}

I would like to thank the staff of the Warner Mountain Ranger District, especially wildlife biologist Mary Flores, for providing guidance, assistance, and housing during the field portion of my study. The staff members were extremely helpful and welcoming towards me. They were always available and willing to discuss ideas, share equipment, and provide advice. I would like to extend extra appreciation to Mary Flores. Mary spent countless hours in the field, helping me locate nest sites, and showing me territories that have been active nesting areas in the past. She provided me with pellets and prey remains that had been collected in previous years (1996-1999), and graciously allowed me to analyze them for use in my study. In addition, Mary provided me with any equipment I needed, as well as a government vehicle to use while searching for nest sites. This study would not have been possible without her knowledge and guidance.

I wish to thank my sisters, Gina and Lisa Promessi, for their emotional support and encouragement throughout the duration of my study. Special thanks is extended to my parents, David and Barbara Promessi, for instilling in me the value of education, and providing me with the tools necessary to become successful. The love, support, and encouragement of my entire family have been invaluable to me throughout my education and my life. 
I would like to thank Jesse West for spending countless hours helping me dissect pellets, as well as her support, encouragement, and friendship. I also wish to thank the members of my committee, Dr. John Matson, Dr. Sulekha Anand, and Dr. Rod Myatt, for their input and advice throughout each step of my project. Special gratitude is reserved for my major advisor, Dr. John Matson. Dr. Matson provided me with several opportunities as a graduate student, including the opportunity to teach biology laboratories for undergraduate students. Throughout the graduate program, I was able to assist him in lecture based classes and learn effective teaching, as well as research techniques. He is thanked for his input, guidance, and patience throughout the duration of my project. He is especially thanked for sharing his passion for the Warner Mountains with me, and sparking my own interest in the region. 


\section{Page}

LIST OF TABLES...........................................................vii

INTRODUCTION...............................................................

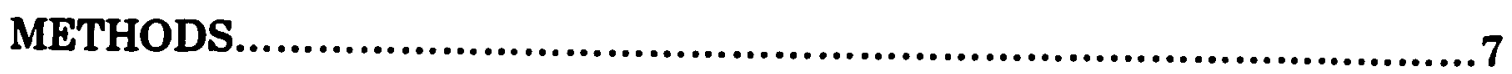

Study Area................................................................

Habitat Evaluation......................................................8

Determination of Diet........................................................9

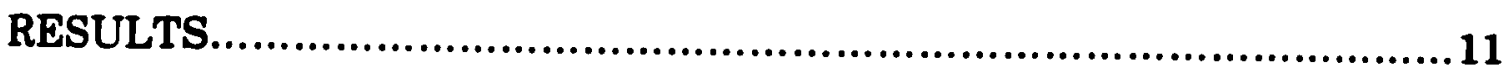

Habitat Evaluation.......................................................11

Determination of Diet....................................................14

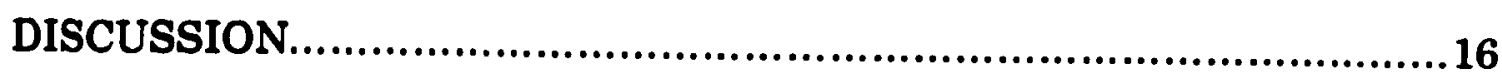

Habitat Evaluation.....................................................16

Determination of Diet.....................................................18

Suggestions for Future Research..........................................22

LITERATURE CITED.....................................................23 


\section{LIST OF TABLES}

Table

Page

1 Mean $\mathrm{dbh}$, mean canopy cover, and tree species composition of seven Northern Goshawk nesting sites

2 Species, dbh, tree height, nest height, and canopy

cover of Northern Goshawk nest trees

$3 \quad$ Northern Goshawk prey determined from

examining pellets and prey remains collected at

23 nesting sites in the Warner Mountains, CA....................15

4 Mammals and birds comprising $\geq 5 \%$ of the

identified prey taken by Northern Goshawks

in the Warner Mountains.

5 Frequency of birds and mammals determined by

studies conducted in various regions of North

America............................................................20 


\section{INTRODUCTION}

The Northern Goshawk (Accipiter gentilis) is a large predatory bird. The species is considered holarctic in distribution, occupying temperate and boreal forests across North America, Europe and Asia (Reynolds et al. 1994, Squires and Reynolds 1997). The North American subspecies, Accipiter gentilis atricapilus, inhabits deciduous, coniferous, and mixed forests of montane regions across the continent (Reynolds et al. 1994, Bosakowski 1999). For the purposes of this study, the term Northern Goshawk will be used to refer to the North American subspecies.

Northern Goshawks are well adapted for hunting in mature, old • growth forests. They possess relatively short, rounded wings and long tails, allowing them to maneuver between tree trunks and branches in pursuit of prey (Palmer 1988, Squires and Reynolds 1997, Bosakowski 1999). Northern Goshawks are considered opportunistic feeders, eating a wide variety of prey depending on location, season, and species availability (Boal and Mannan 1994, Squires and Reynolds 1997, Bosakowski 1999). Their diet consists primarily of birds and mammals, but they may consume reptiles and insects on occasion (Squires and Reynolds 1997).

Prior to consumption, Northern Goshawks regularly remove the hair and feathers from their prey. In addition, Northern Goshawks regurgitate pellets containing bones and keratinous parts that are not easily digestible 
(Reynolds and Meslow 1984). These behaviors take place either at the nest site itself, or at perches commonly referred to as "plucking posts" (Reynolds and Meslow 1984, Bosakowski 1999). Plucking posts usually consist of logs, stumps, snags, and/or overhead branches that are typically located close to the nesting tree (Bosakowski 1999). In addition to pellets, prey remains, which can be defined as bones, hair, and feathers not contained within a pellet, are commonly found at the base of nest trees and plucking posts. By collecting and examining pellet contents and prey remains, it is possible to identify the various species that have been taken as prey (Reynolds and Meslow 1984). While there are biases associated with the determination of diet from pellet contents and prey remains (Reynolds and Meslow 1984, Marti 1987), studies have shown the method to sufficiently represent the food habits of raptors (Callopy 1983, Real 1966).

Because the diet of Northern Goshawks varies regionally, studies of populations across its range are necessary to fully understand the food habits of the species as a whole (Storer 1966, Boal and Mannan 1994, Squires 2000). For example, the ratio of avian to mammalian prey items is one aspect of Northern Goshawk diets that varies regionally. According to Bosakowski et al. (1992), Northern Goshawks in the New Jersey-New York Highlands rely more heavily on avian than mammalian prey items. Of 231 total prey items captured by nesting Northern Goshawks in the region, $30 \%$ were identified as 
mammals, while $70 \%$ were identified as birds (Bosakowski et al. 1992). Meng (1959) reported a similar trend after identifying a total of 185 prey items taken by nesting Northern Goshawks in Pennsylvania and New York. Of these 185 prey items, $39 \%$ were identified as mammals while $61 \%$ were identified as birds. Similarly, Grzybowski and Eaton (1976) reported the same percentages of birds and mammals found by Meng (1959) after examining 77 prey items taken by Northern Goshawks in southwestern New York.

In boreal and western forests, where lagomorphs and ground squirrels are more abundant than in eastern forests, mammalian prey items become more important components of the diet (Bosakowsi, 1999). Boal and Mannan (1994) found ground squirrels to be the most abundant prey item of Northern Goshawks nesting on the Kaibab Plateau in northern Arizona. In this region, mammals represented $76 \%$ of the prey items identified while birds represented $24 \%$ of all prey items identified. In the same region, Reynolds et al. (1994) reported that $62 \%$ of the 121 prey items identified were mammals, and $38 \%$ of the prey items identified were birds. According to Doyle and Smith (1994), snowshoe hares and arctic ground squirrels comprised the majority of the diet of Northern Goshawks nesting in the Yukon Territory. They reported that out of $\mathbf{4 1 0}$ total prey items captured by Northern Goshawks, $76 \%$ were mammals while only $24 \%$ were birds. The findings of 
similar food habit studies conducted by Younk and Bechard (1994) in Nevada and McCoy (1999) in the Cascade Mountains of northern California follow the same trend of mammalian prey items exceeding the number of avian prey items in western and boreal forests.

Although studies conducted in eastern Oregon and Washington found that the total number of avian prey exceeded the total number of mammalian prey, there was still a clear increase in the percentage of mammals in the diet compared to studies conducted in the east (Reynolds and Meslow 1984, Bull and Hohmann 1994, Watson et al. 1998). Reynolds and Meslow (1984) identified 227 prey items in northwestern and eastern Oregon. They reported that $55 \%$ of the prey items identified were birds while $45 \%$ were mammals. In northeastern Oregon, Bull and Hohmann (1994) identified 94 prey items taken by nesting Northern Goshawks. Of these prey items, $41 \%$ were identified as mammals, while $\mathbf{5 9 \%}$ were identified as birds. One notable exception to this trend is reported by Schnell (1958). In his study conducted in the Sierra Nevada of California, Schnell (1958) identified a total of 88 prey items, $69 \%$ of which were birds and $31 \%$ of which were mammals. His findings are not consistent with other studies conducted in western North America, and report a much larger frequency of birds than mammals in the diet. However, Schnell (1958) examined prey items at only one nest site, and 
therefore the results of his study may not be representative of the food habits of the Sierra Nevada population as a whole.

Northern Goshawks typically nest in mature or old growth forests with relatively closed canopies (Reynolds et al. 1982, Speiser and Bosakowski 1987, Hayward and Escano 1989, Squires and Reynolds 1997, Bosakowski 1999). In nest stands, understory trees and ground cover are typically sparse or absent, apparently allowing for more efficient foraging (Squires and Reynolds 1997, Bosakowski 1999). Despite these overall similarities in nesting sites (mature stands, closed canopies, and sparse understories), Northern Goshawks have been reported to nest in a wide variety of forest types (Palmer 1988, Bosakowski 1999). In New Jersey and New York, Speiser and Bosakowski (1987) reported a preference for mixed forest stands dominated by hardwoods and conifers. Nesting was also reported in pure deciduous forests and pine plantations (Speiser and Bosakowsi 1987). In Oregon, conifer stands of pure lodgepole pine, or stands of mixed lodgepole and ponderosa pine were preferred (Reynolds et al. 1982). According to Shuster (1980), stands of aspen were preferred over conifer stands in the Colorado Rockies.

The Warner Mountains of California is a mountain range that supports a nesting population of Northern Goshawks (M. Flores, Personal Communication). Although the food habits of Northern Goshawks nesting in 
surrounding regions have been examined (McCoy 1999, Schnell 1958, Reynolds and Meslow 1984), the Warner Mountain population has not yet been thoroughly investigated. Bloom et al. (1986) reported the food habits of Northern Goshawks nesting in various regions of California, including the Warner Mountain area. However, the 234 prey items that they examined were collected from several different regions of the state, and it is unclear how many came from the Warner Mountains. Northern Goshawk diets vary regionally and therefore it is important to investigate the food habits of individual Northern Goshawk populations to fully understand the species as a whole (Storer 1966, Boal and Mannan 1994). The purpose of this study was to determine the food habits of Northern Goshawks nesting in the Warner Mountains by analyzing their pellets and prey remains. Specifically, the hypothesis tested was that Northern Goshawks in the Warner Mountains take significantly more mammals than birds as prey. This hypothesis was formulated because the Warner Mountains are in the western United States where small mammals, such as ground squirrels and lagomorphs, are more abundant than in eastern forests (Bosakowski, 1999). In addition, the habitat compositions of the forest stands containing active Northern Goshawk nests are described. The present study focused on the Warner Mountain region because although it supports a viable population of 
Northern Goshawks (M. Flores, Personal Communication), limited research has been conducted in the area.

\section{METHODS}

Study Area

This study was conducted in the Warner Mountains, located on the eastern border of the Modoc Plateau in the extreme northeast corner of California. The Warner Mountains are a faulted range and are volcanic in origin (Schoenherr 1992, Hickman and Roberts, 1993). The highest point of the range, Eagle Peak, extends above 3000 m (Hickman and Roberts, 1993). The Warner Mountains comprise one of four Ranger Districts of the Modoc National Forest, and is managed by the United States Forest Service (USFS). Although the northern end of the range extends into southeast Oregon, this study was conducted in California and did not include the small portion of the range found outside of the state. The Warner Mountain range is divided into northern and southern regions by Cedar Pass, which extends from Alturas in the west to Cedarville in the east. Much of the range is composed of mixed conifer forests, with ponderosa pine (Pinus ponderosa) and white fir (Abies concolor) occurring frequently at moderate elevations (Schoenherr 1992, M. Flores, Personal Communication). Northern Goshawks have been 
known to nest in these forests throughout the Warner Mountain range (Bloom et al. 1986, M. Flores, Personal Communication).

\section{Habitat Evaluation}

During the summer of 2001, nests and plucking posts were located in the Warner Mountains by surveying areas containing suitable Northern Goshawk habitat. Surveys focused on regions in which nests have been located in the past by members of the USFS. In the summer of 2001, twelve nest sites were located. Seven of these twelve were determined to be active nesting sites for the 2001 season. These active nest sites are referred to as Del Pratt, Rock Lake, East Creek, Shields Creek, Fitzhugh Creek, Smalls Canyon, and Hacker Flat. The active nest stands were evaluated for habitat composition with the exception of the East Creek site, which burned in August of that year. In addition to the remaining six active nest sites, one other stand was evaluated (Ski Hill) due to the high level of Northern Goshawk activity in that area during previous years. Therefore, a total of seven nest stands were evaluated for habitat composition.

The species and diameter at breast height $(\mathrm{dbh})$ of the nest tree were recorded, and canopy cover at the nest tree was determined using a Model $\mathrm{A}$ spherical densiometer. Tree height and nest height were measured using a Suunto clinometer with percent and per chain scales. Beginning at the nest 
tree, transect lines of $91.44 \mathrm{~m}(300 \mathrm{ft})$ were set in each cardinal direction. Sample points were marked every $15.24 \mathrm{~m}(50 \mathrm{ft})$ along each transect line. At each sample point, the identity of the closest tree to the north, south, east, and west was recorded. The dbh of each tree was measured and the canopy cover at each point was determined with the densiometer.

\section{Determination of Diet}

Once located, all nest sites and plucking posts were examined for pellets and prey remains. Any pellets and/or prey remains found were collected in plastic bags, labeled, and stored for subsequent analysis. Each collection from a given nest site was considered to be one sample, and each of these samples consisted of several pellets and prey remains. In addition to samples collected in 2001, samples that were collected in previous years (1996 1999$)$ by members of the USFS were examined and included in the data for this study.

All samples were examined and analyzed at San Jose State University. When examining samples, individual pellets were dissected by hand as described by Marti (1987). Pellets were broken into smaller pieces and forceps were used to remove the hair and/or feathers from teeth, bones, and other identifiable parts. Pellet contents and prey remains were then identified to species when possible. Reference specimens from the Museum of 
Birds and Mammals at San Jose State University were used along with relevant taxonomic keys to identify prey species. When the identity of a specimen could not be determined, pellet contents and prey remains were simply identified as either bird or mammal. Each sample collected was analyzed separately. Bones, teeth, hair, and feathers were separated and matched (feathers, beaks, and bones of birds, and the bones, teeth, and hair tufts of mammals) so that the minimum number of individuals per sample could be determined. Remains of the same species were counted as more than one individual only if there were more than one of the same identifying item present. For example, remains of the same species were considered to be two individuals if two right mandibles for that species were found. The species composition, minimum number of individuals, and total number of occurrences of mammalian versus avian prey items in each sample were determined and recorded. A chi-square goodness of fit analysis was used to determine if there was a significant difference in the number of birds versus mammals identified. Specifically, chi-square analysis was performed on the minimum number of individuals, and on the total number of occurrences of mammals and birds. 


\section{RESULTS}

\section{Habitat Evaluation}

Active Northern Goshawk nests in the Warner Mountains were located in conifer stands containing primarily White Fir (Abies concolor) and Ponderosa Pine (Pinus ponderosa). In addition, Jeffrey Pine (Pinus jeffrey) was found at the Hacker Flat site, and Incense Cedar (Calocedrus decurrens) was found at the Rock Lake site (Table 1). White Fir was encountered most frequently and accounted for a mean of $67.44 \%$ cf trees measured at all nest sites. It was also the most common species at each individual nest site, with the exception of Hacker Flat. Jeffrey Pine was encountered least frequently, accounting for a mean of only $1.38 \%$ of all trees measured. Nest stands were composed of fairly large trees (mean $\mathrm{dbh}=39.81 \mathrm{~cm}$ ) and had a high degree of canopy cover $($ mean $\mathbf{= 8 4 . 5 3 \%})$.

Three of the seven nest trees measured were White Fir, while four were Ponderosa Pine (Table 2). The seven nest trees measured had a mean $\mathrm{dbh}$ of $60.07 \mathrm{~cm}$, which exceeded the mean $\mathrm{dbh}$ of all trees measured (39.81 $\mathrm{cm}$. There was also an increase in the mean canopy cover at the nest tree (92.46\%) compared to the mean canopy cover measured along all transect lines (84.53\%). 


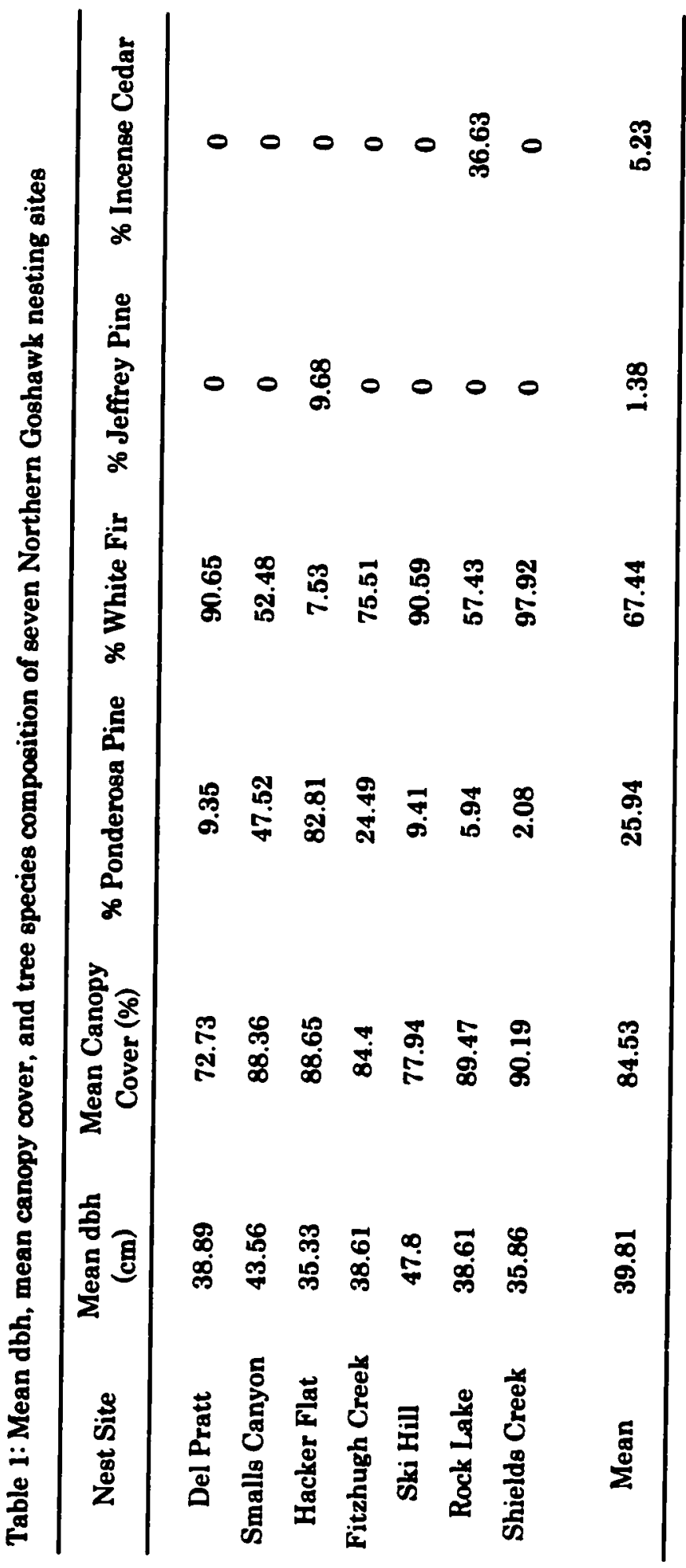




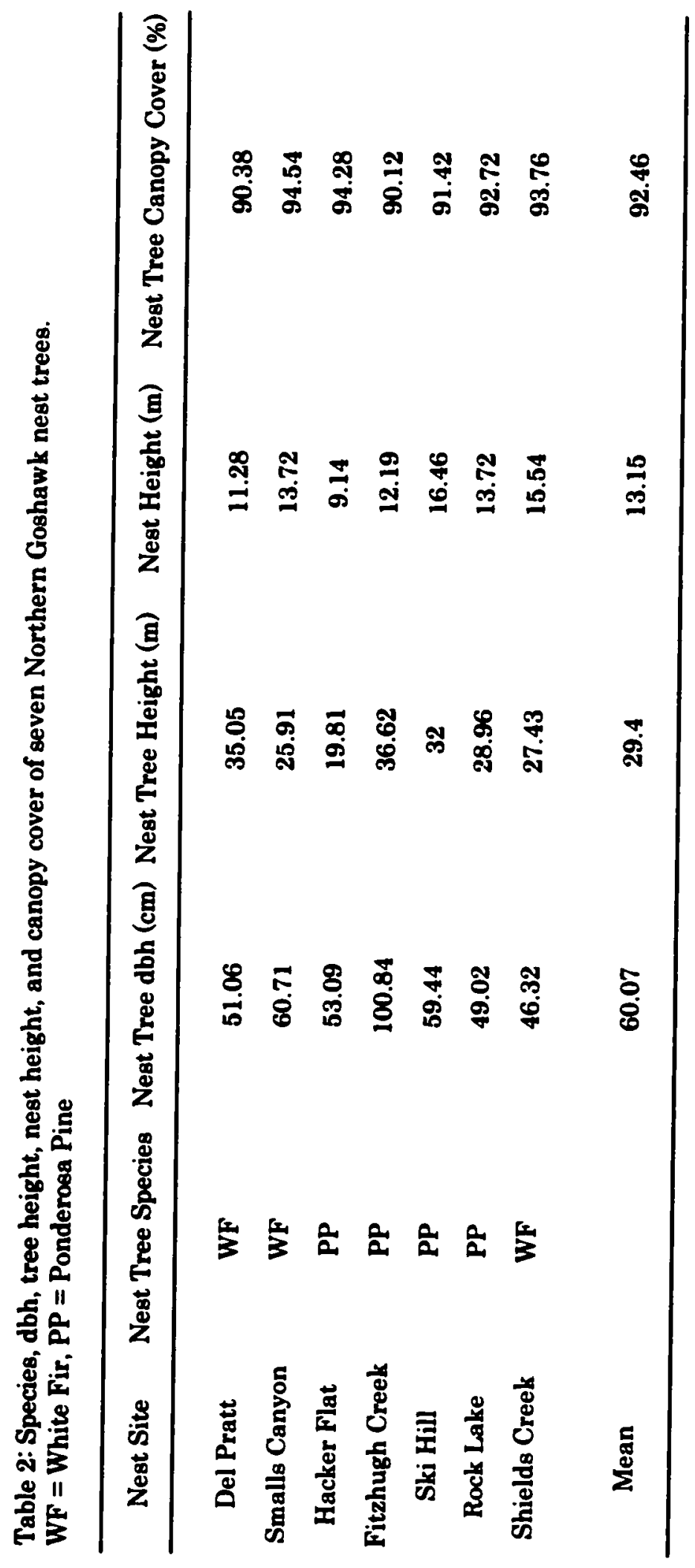




\section{Determination of Diet}

During the summer of 2001, a total of 22 samples were collected from 12 different nest sites found in the Warner Mountains. Of these 12 nest sites, seven (Rock Lake, East Creek, Shields Creek, Fitzhugh Creek, Smalls Canyon, and Hacker Flat) were determined to be active sites in 2001. In addition to the 22 samples collected in 2001,11 samples from 11 different nest sites collected in previous years were examined and included in the data for this study.

Northern Goshawks in the Warner Mountains of California consumed at least 13 different mammalian prey species and 17 different avian prey species (Table 3). Both methods of quantifying prey items (minimum number of individuals and total number of occurrences) revealed a significantly higher proportion of mammals than birds. When counting the minimum number of prey items, 221 unique individuals were identified. Of these, $126(57.01 \%)$ were mammals and $95(42.99 \%)$ were birds. Statistical analysis revealed that these numbers represent a significantly higher proportion of mammals than birds identified in all samples $\left(x^{2}=4.348, d f=1\right.$, $p \leq 0.05$ ). In addition, there was a significant difference in the total number of occurrences of mammals and birds in pellets and prey remains $\left(x^{2}=\right.$ 14.098, $\mathrm{df}=1, \mathrm{p} \leq 0.05$ ). When examining the total number of occurrences, 
Table 3: Northern Goshawk prey determined from examining pellets and prey remains collected at 23 nesting sites in the Warner Mountains, CA

\begin{tabular}{|c|c|c|}
\hline Species & $\begin{array}{l}\text { Minimum \# of } \\
\text { Individuals Identified }\end{array}$ & $\begin{array}{c}\text { Total \# of } \\
\text { Occurrences in Pellets } \\
\text { and Prey Remains }\end{array}$ \\
\hline \multicolumn{3}{|l|}{ MAMMALS: } \\
\hline Tamiasciurus douglasi & 22 & 55 \\
\hline Spermophilus lateralis & 22 & 37 \\
\hline Spermophilus beldingi & 16 & 24 \\
\hline Spermophilus beecheyi & 2 & 2 \\
\hline Unknown Spermophilus sp. & 13 & 21 \\
\hline Tamias sp. & 16 & 29 \\
\hline Sylvilagus sp. & 6 & 7 \\
\hline Lepus sp. & 4 & 4 \\
\hline Unknown Lagomorph & 1 & 1 \\
\hline Mustela frenata & 1 & 2 \\
\hline Glaucomys sabrinus & 1 & 1 \\
\hline Peromyscus maniculatus & 1 & 1 \\
\hline Sorex sp. & 2 & 2 \\
\hline Microtus sp. & 1 & 1 \\
\hline Neotoma cinerea & 1 & 1 \\
\hline Unidentified Mammal & 19 & 49 \\
\hline Total Mammals & $126(57.01 \%)$ & $237(59.40 \%)$ \\
\hline \multicolumn{3}{|l|}{ BIRDS: } \\
\hline Colaptes auratus & 15 & 24 \\
\hline Cyanositta stelleri & 13 & 13 \\
\hline Turdus migratorius & 8 & 8 \\
\hline Dendragapus obscurus & 5 & 5 \\
\hline Sphyrapicus thyroideus & 3 & 3 \\
\hline Oreortyx pictus & 3 & 3 \\
\hline Piranga ludoviciana & 2 & 2 \\
\hline Carduelis pinus & 2 & 2 \\
\hline Agelaius phoeniceus & 2 & 2 \\
\hline Dendroica coronata & 1 & 1 \\
\hline Aegolius acadicus & 1 & 1 \\
\hline Bombycilla sp. & 1 & 1 \\
\hline Picoides pubescens & 1 & 1 \\
\hline Phasianus colchicus & 1 & 1 \\
\hline Sitta sp. & 1 & 1 \\
\hline Spizella sp. & 1 & 1 \\
\hline Perisoreus canadensis & 1 & $i$ \\
\hline Unidentified Bird & 27 & 92 \\
\hline Total Birds & $95(42.99 \%)$ & $162(40.60 \%)$ \\
\hline TOTAL PREY ITEMS & 221 & 399 \\
\hline
\end{tabular}


$237(59.40 \%)$ instances of mammals and $162(40.60 \%)$ instances of birds were recorded (Table 3).

Ground squirrels (Spermophilus sp.) were most commonly found, accounting for $42.06 \%$ of the mammals identified and $23.98 \%$ of all prey species identified (Table 4). Other frequently occurring prey items $(\geq 5.00 \%$ of all prey species identified) included Douglas Squirrel ( Tamiasciurus douglasi), Chipmunk (Tamias sp.), Northern Flicker (Colaptes auratus), Steller's Jay (Cyanositta stelleri) and Lagomorphs (Sylvilagus sp. or Lepus sp.).

\section{DISCUSSION}

\section{Habitat Evaluation}

In the Northwestern region of the United States, Northern Goshawks frequently utilize nest stands composed primarily of conifer trees (Reynolds et al. 1982, Moore and Henry 1983, Bull and Hohmann 1994). Similarly, nesting Northern Goshawks in the Warner Mountains seem to prefer conifer stands, with Ponderosa Pine and White Fir trees occurring most frequently. Shuster (1980) reported that Northern Goshawks in the Colorado Rockies preferred aspen stands as opposed to conifer stands. Although there are several stands of aspen throughout the Warner Mountain range (M. Flores, 
Table 4: Mammals and birds comprising $\geq 5 \%$ of the identified prey taken by Northern Goshawks in the Warner Mountains. Figures based on the minimum number of individuals identified.

\begin{tabular}{lcc}
\hline \multicolumn{1}{c}{ Species } & $\begin{array}{c}\text { \% of Category (Bird or } \\
\text { Mammal) }\end{array}$ & $\begin{array}{c}\text { \% of All Individuals } \\
\text { Identified }\end{array}$ \\
\hline MAMMALS: & & \\
Ground Squirrel & 42.06 & 23.98 \\
Douglas Squirrel & 17.46 & 9.95 \\
Chipmunk & 12.69 & 7.24 \\
Lagomorph & 8.73 & 5.00 \\
& & \\
BIRDS: & & 6.79 \\
Northern Flicker & 15.79 & 5.88 \\
Steller's Jay & 13.68 & \\
\hline
\end{tabular}


Personal Communication), no Northern Goshawk nests were discovered in aspen trees during the present study. However, time constraints in the present study did not allow for an exhaustive search of all aspen stands in the region. Future studies should be done to survey these areas for Northern Goshawk activity.

The preferred habitat characteristics of Northern Goshawks seem to be fairly consistent throughout the range of the species (Bosakowsi 1999), and the nest sites found in the Warner Mountain range fit into the general pattern observed in other regions (Reynolds et al. 1982, Speiser and Bosakowski 1987, Hayward and Escano 1989, Bull and Hohmann 1994, Squires and Reynolds 1997). Nest stands were composed primarily of large diameter trees and had a high degree of canopy cover.

\section{Determination of Diet}

Based on the analysis of pellets and prey remains, Northern Goshawks nesting in the Warner Mountains appear to prey more heavily on mammals than birds. The prey of Warner Mountain Northern Goshawks was quantified using two different methods: the minimum number of individuals was determined, and the total number of occurrences of mammalian and avian prey items was counted. It is worth noting that both methods reveal similar percentages of mammals and birds in the diet. When using the minimum 
number method, mammals represent $57.01 \%$ of prey while birds represent $\mathbf{4 2 . 9 9 \%}$ of prey. Similarly, mammals represent $\mathbf{5 9 . 4 0 \%}$ of prey and birds represent $40.60 \%$ of prey when using the total number of occurrence method.

The findings of the present study support the idea that Northern Goshawks nesting in western North America take more mammals as prey than Northern Goshawks nesting in the eastern portion of the continent. The data reported here are consistent with other studies that have been conducted throughout the western region of the United States (Boal and Mannan 1994, Reynolds et al. 1994, Younk and Bechard 1994, McCoy 1999). Table 5 summarizes the frequencies of avian and mammalian prey items identified by previous studies conducted in various regions of North America. Of the ten studies conducted in the western portion of the continent, six reported a significant difference in the number of birds and mammals identified (Schnell 1958, Boal and Mannan 1994, Reynolds et al. 1994, Younk and Bechard 1994, McCoy 1999, Present Study 2002). Of these six studies, all found that the minimum number of mammals identified exceeded the minimum number of birds, with the exception of Schnell (1958). Schnell's findings suggest that Northern Goshawks in the Sierra Nevada of California take a larger number of birds than mammals, despite foraging in a western forest where the availability of mammalian prey items is greater than in eastern forests. A possible explanation for these findings is that Schnell 


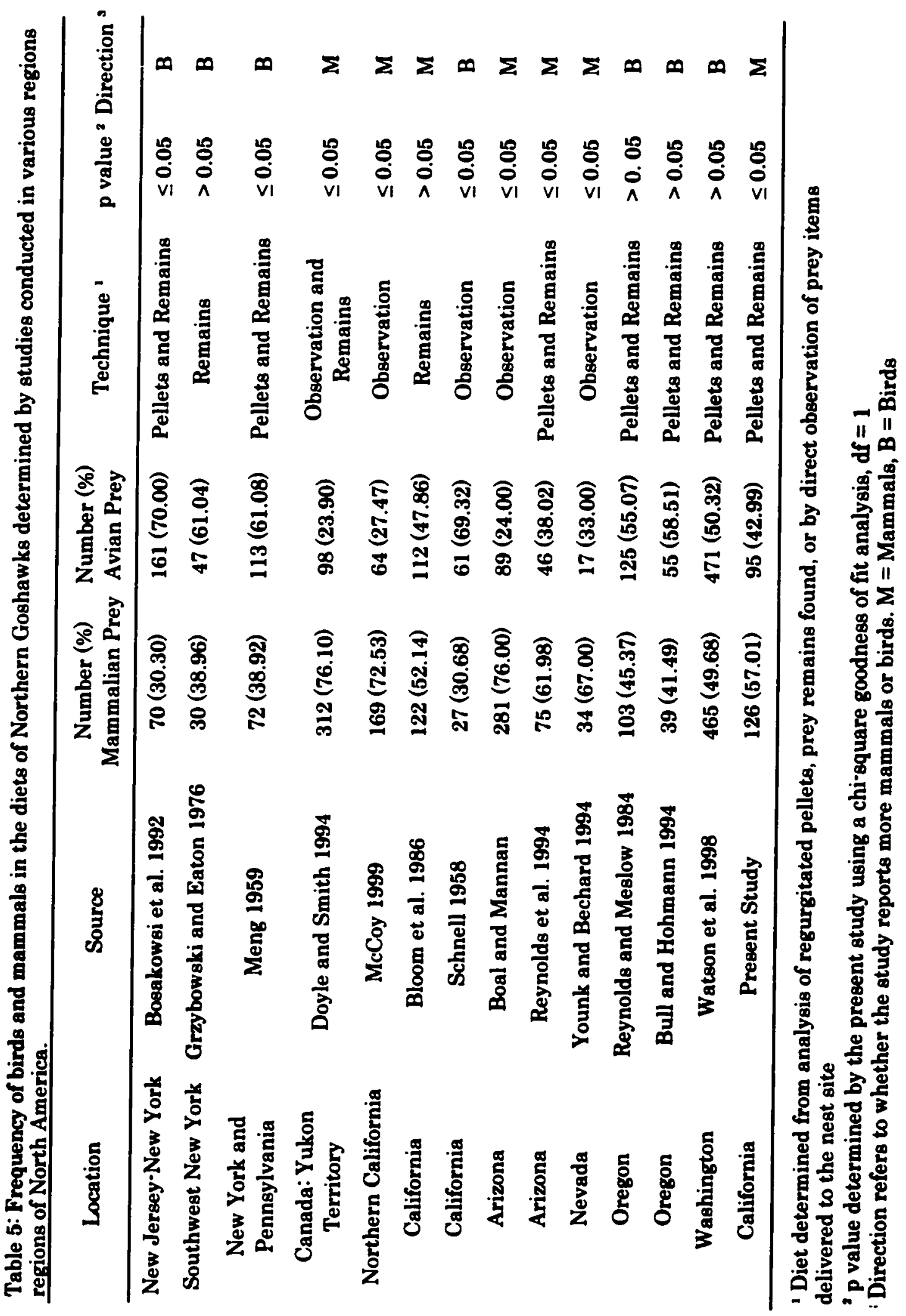


(1958) examined prey items at only one nest site in the Sierra Nevada. Therefore, his findings reflect the food habits of only one nesting pair of Northern Goshawks as opposed to the entire Sierra Nevada population. It is possible that the food habits of the nesting pair observed differed from other nesting pairs, and do not reflect the habits of the population as a whole.

Although the findings of this study are consistent with other studies conducted in western North America that report a significant difference in the number of birds and mammals identified (Boal and Mannan 1994, Reynolds et al. 1994, Younk and Bechard 1994, McCoy 1999), studies conducted in eastern North America have reported the opposite trend. Research has shown that Northern Goshawks take a significantly higher proportion of birds than mammals in New York, New Jersey, and Pennsylvania (Meng 1959, Bosakowski et al. 1992). The differences observed between the two regions of the continent can be attributed to differences in small mammal populations (Bosakowski, 1999). In western and boreal forests, small mammals such as lagomorphs and ground squirrels are more abundant than in eastern forests. It appears that the increase in small mammal abundance in the west translates to more mammals being available to Northern Goshawks as prey. 


\section{Suggestions for Future Research}

Although it appears that Northern Goshawks in the Warner

Mountains prey more heavily on mammals than those in the eastern United States due to the higher abundance of small mammals in western forests, the abundances of small mammal populations in the Warner Mountains were not quantified in this study. Future studies should focus on small mammal trapping in Northern Goshawk nest stands found in the Warner Mountains. This data would help to determine whether or not the diet of Northern Goshawks as determined by the analysis of pellets and prey remains is correlated to the relative abundances of small mammal species occupying nest stands. Similarly, it would be worthwhile to survey bird populations to establish whether a correlation exists between the data collected from pellet and prey remains, and the abundances of relevant bird species. In addition, it would be useful to investigate Northern Goshawk food habits during different seasons throughout the year. It would be interesting to examine if the diet fluctuates in different seasons, and if so, whether or not that difference is correlated with changes in small mammal and bird populations. 


\section{LITERATURE CITED}

BLOOM, P. H., G. R. STEWART, and B. J. WALTON. 1986. The status of the Northern Goshawk in California, 1981-1983. Administrative Report 85-1. State of California, Department of Fish and Game, Sacramento.

BOAL, C. W. and R. W. MANNAN. 1994. Northern Goshawk diets in ponderosa pine forests on the Kaibab Plateau. Studies in Avian Biology 16:97-102.

BOSAKOWSKI, T. 1999. The Northern Goshawk: Ecology, Behavior, and Management in North America. Hancock Wildlife Raptor Series. Hancock House Publishers, Blaine, WA. 80 pgs.

BOSAKOWSKI, T., D. G. SMITH, and R. SPEISER. 1992. Niche overlap of two sympatric'nesting hawks Accipiter spp. in the New Jersey-New York Highlands. Ecography 15:358-372.

BULL, E. L. and J. H. HOHMANN. 1994. Breeding biology of Northern Goshawks in northeastern Oregon. Studies in Avian Biology 16:103. 105.

CALLOPY, M. W. 1983. A comparison of direct observations and collections of prey remains in determining the diet of Golden Eagles. Journal of Wildlife Management. 47(2):360-368

DOYLE, F. I. and J. M. N. SMITH. 1994. Population responses of Northern Goshawks to the 10-year cycle in numbers of snowshoe hares. Studies in Avian Biology 16:122-129.

GRZYBOWSKI, J. A. and S. W. EATON. 1976. Prey items of Goshawks in southwestern New York. Wilson Bulletin 88(4):669-670.

HAYWARD, G. D. and R. E. ESCANO. 1989. Goshawk nest-site characteristics in western Montana and northern Idaho. Condor 91:476:479.

HICKMAN, J.C. and ROBERTS, W. 1993. Geographic subdivisions of California. Pp. 37-44 in The Jepson Manual: Higher Plants of California. (J.C. Hickman, Ed.). University of California Press, Berkeley. 
MARTI, C. D. 1987. Raptor food habits studies. Pp. 67-80 in Raptor management Techniques manual. (B. A. G. Pendleton, B. A. Millsap, K. W. Cline, D. M. Bird, Eds.). National Wildlife Federation, Washington, D.C.

McCOY R. H. 1999. Effects of prey delivery on the fledging success of the Northern Goshawk. M.S. Thesis. Humbolt State University, Arcada.

MOORE, K. R., and HENNY, C. J. 1983. Nest site characteristics of three coexisting Accipiter Hawks in northeastern Oregon. Raptor Research 17(3):65-76.

MENG, H. 1959. Food habits of nesting Cooper's Hawks and Goshawks in NewYork and Pennsylvania. Wilson Bulletin 71(2):169-174.

PALMER, R. S. (Ed.). 1988. Handbook of North American Birds. Diurnal Raptors vol. 4. Yale University Press, New Haven, CT. pgs. 355-378.

REAL, J. 1996. Biases in the diet study methods in the Bonelli's Eagle. Journal of Wildlife Management. 60(3):632-638

REYNOLDS, R. T., E. C. MESLOW, and H. M. WIGHT. 1982. Nesting habitat of coexisting Accipiter in Oregon. Journal of Wildlife Management 46(1):124-138.

REYNOLDS, R. T. and E. C. MESLOW. 1984. Partitioning of food and niche characteristics of coexisting Accipiter during breeding. Auk 101:761779.

REYNOLDS, R. T., S. M. JOY, D. G. LESLIE. 1994. Nest productivity, fidelity, and spacing of Northern Goshawks in Arizona. Studies in Avian Biology 16:106-113.

SCHOENHERR, A. A. 1992. A Natural History of California. University of California Press, Berkeley and Los Angeles, CA., University of California Press, Ltd., London, England. 772 pgs.

SCNHELL J. H. 1958. Nesting behavior and food habits of Goshawks in the Sierra Nevada of California. Condor 60:377 403 .

SHUSTER, W. C. 1980. Northern Goshawk nesting requirements in the Colorado Rockies. Western Birds 11: 89-96. 
SPEISER, R. and T. BOSAKOWSKI. 1987. Nest site selection by Northern Goshawks in northern New Jersey and southeastern New York. Condor 89:387-394.

SQUIRES, J. R. 2000. Food habits of Northern Goshawks nesting in south central Wyoming. Wilson Bulletin 112(4): 536-539.

SQUIRES, J. R., and R. T. REYNOLDS. 1997. Northern Goshawk (Accipiter gentilis). Pp. 1-31 in The birds of North America, no. 298. (A. Poole and F. Gill, Eds.). The Academy of Natural Sciences, Philadelphia, PA; The American Ornithologists' Union, Washington, D.C.

STORER, R. W. 1966. Sexual dimorphism and food habits in three North American Accipiters. Auk 83:423:436.

WATSON, J. W., D. W. HAYS, and S. P. FINN. 1998. Prey of breeding Northern Goshawks in Washington. Journal of Raptor Research 32(4): 297-305.

YOUNK, J. V. and M. J. BECHARD. 1994. Breeding ecology of the NorthernGoshawk in the high-elevation aspen forests on northern Nevada Studies in Avian Biology 16:119-121. 